\title{
Anatomy of the Thoracic Wall, Axilla and Breast
}

\author{
Anatomía de la Pared Torácica, Axila y Mama \\ *José Rafael Macéa \& *** José Humberto Tavares Guerreiro Fregnani
}

\begin{abstract}
MACÉA, J. R. \& FREGNANI, J. H. T. G. Anatomy of the thoracic wall, axilla and breast. Int. J. Morphol., 24(4):691-704, 2006.
SUMMARY: For adequate treatment of patients with breast cancer, mastologists should have a complete understanding of the anatomy of the thoracic wall, axilla and breast. However, the classical anatomical descriptions in textbooks make it difficult to gain full mastery of this subject, because the books usually deal with its elements separately. In an endeavor to resolve this difficulty, the present authors have conducted an extensive review, to describe the muscles, blood vessels and nerves of the thoracic wall and in the axilla that are of interest to mastologists. The axilla was described in detail, with emphasis on its limits, walls and contents, and highlighting the lymph nodes in this region. Finally, the anatomy of the breast and its topography, innervation, vascularization and lymph drainage were described, making correlations between the anatomy and the lymph node group classification routinely used by mastologists.
\end{abstract}

KEY WORDS: Thoracic wall; Axilla; Breast; Anatomy.

\section{INTRODUCTION}

The great advances achieved in the surgical treatment of breast cancer have made it essential for mastologists to have detailed knowledge of all anatomical features of the breast and its syntopy with the thoracic wall and axillary region. Knowledge of the axillary region is particularly important, as this is the usual location for surgical interventions forming part of the treatment for this neoplasm that is so common. However, integrated study of these three topics is not always easy, since these are subjects that have historically been described separately in the classical anatomy textbooks. Within this context, we had the aim of making a detailed and integrated review of the anatomy of the breasts, the thoracic wall related to the breast and also the axillary region.

We started the review by studying the thoracic wall, particularly with regard to its muscles, vessels and nerves that are of interest to mastology. Following this, we dealt with the anatomy of the axilla, emphasizing its limits, walls and content. We made a detailed study of the muscles that constitute its walls, together with the corresponding innervation. We also described the plexus brachialis, with its trunks, fascicles and nerves, and correlated them with the arteries and veins that occupy the axillary space. Finally, we studied the anatomy of the breast, its topography, innervation, vascularization and lymphatic drainage, and correlated the anatomical data with the classification of lymph node groups that is frequently utilized by mastologists.

Anatomy of the thoracic wall. The skeleton of the thoracic wall is formed by the twelve thoracic vertebra posteriorly, the sternum anteriorly and, on each side, by the twelve ribs and the respective costal cartilage. The spaces between the ribs are filled by the intercostal musculature, which consists of three layers. The intercostalis externus muscle, with fibers oriented inferoanteriorly, extends posteriorly from the plane of the costal tubercle to the plane of the costochondral articulation. From this point to the sternum, the space is closed by the intercostalis externa membrane (Fig. 1). In the lower intercostal spaces, the fibers of the intercostalis externus muscle interfinger with those of the obliquus externus muscle of the abdomen. The intermediary layer is formed by the intercostalis internus muscle, which has fibers oriented superoanteriorly. This muscle extends from the sternum to the angle of the rib, posteriorly. From there to the transverse process of the corresponding vertebra, the space is occluded by the intercostalis interna membrane. More caudally, its fibers interfinger with those of the obliquus internus muscle of the abdomen. The intercostalis intimus muscle is the deepest layer of the intercostal musculature,

\footnotetext{
* Adjunct Professor and Head of the Department of Morphology of the School of Medical Sciences of Santa Casa de São Paulo, Brasil.

*** Assistant Professor in the Department of Morphology of the School of Medical Sciences of Santa Casa de São Paulo, Brasil. Work developed in the Department of Morphology of the School of Medical Sciences of Santa Casa de São Paulo, Brasil.
} 
and is the least developed of the three. Its fibers are oriented vertically or almost parallel to those of the intercostalis internus muscle. It extends, anteriorly, from the plane of the costochondral articulations to, posteriorly, the plane of the medial margin of the scapula. The neurovascular bundles, protected in the costal groove, are threaded between the intermediary and deep muscle layers, and are responsible for the vascularization and innervation of the intercostal musculature (Lockhart et al., 1959; Williams et al., 1989; Romrell \& Bland, 1998; Drake et al.. 2005).

The pectoralis major muscle (Figs. 1 and 2), which has a triangular shape and is very evident on the anterior thoracic wall, has two origins: one clavicular (medial third of the clavicle) and the other sternocostal (external face of the first seven costal cartilages, lateral margin of the sternum and upper part of the rectus abdominis muscle). The clavicular and sternocostal fibers converge to be inserted into the lateral lip of the intertubercular groove of the humerus. The innervation is performed by the pectoralis medialis and lateralis nerves, which are branches of fasciculus medialis and lateralis of the plexus brachialis, respectively. It forms the anterior axillary fold (Williams et al.; Drake et al.).
The pectoralis minor muscle (Figs. 1 and 2) is located at a deeper level than the pectoralis major muscle, and also has a triangular shape, but of smaller dimensions. It originates from the external face of the third, fourth and fifth ribs and is inserted in the coracoid process of the scapula. It is innervated also by the pectoralis lateralis and medialis nerves (Williams et al.; Drake et al.).

The serratus anterior muscle (Fig. 1) covers most of the lateral thoracic wall and originates as muscle strips from the external face of the first nine ribs. Its fibers converge posteriorly to be inserted into the medial margin of the scapula, thus contributing towards forming the medial wall of the axilla. The more caudal fibers interfinger with those of the obliquus externus muscle of the abdomen. This muscle stabilizes the scapula by exerting traction anteriorly and promoting elevation of the glenoid cavity. The innervation of this muscle is performed by the thoracicus longus nerve (Bell's nerve) (Williams et al.; SBA, 2001; Drake et al.).

The diminutive subclavius muscle (Fig. 2), which is posterior to the costocoracoid ligament of the clavipectoral fascia and difficult to see, originates from the first rib, close

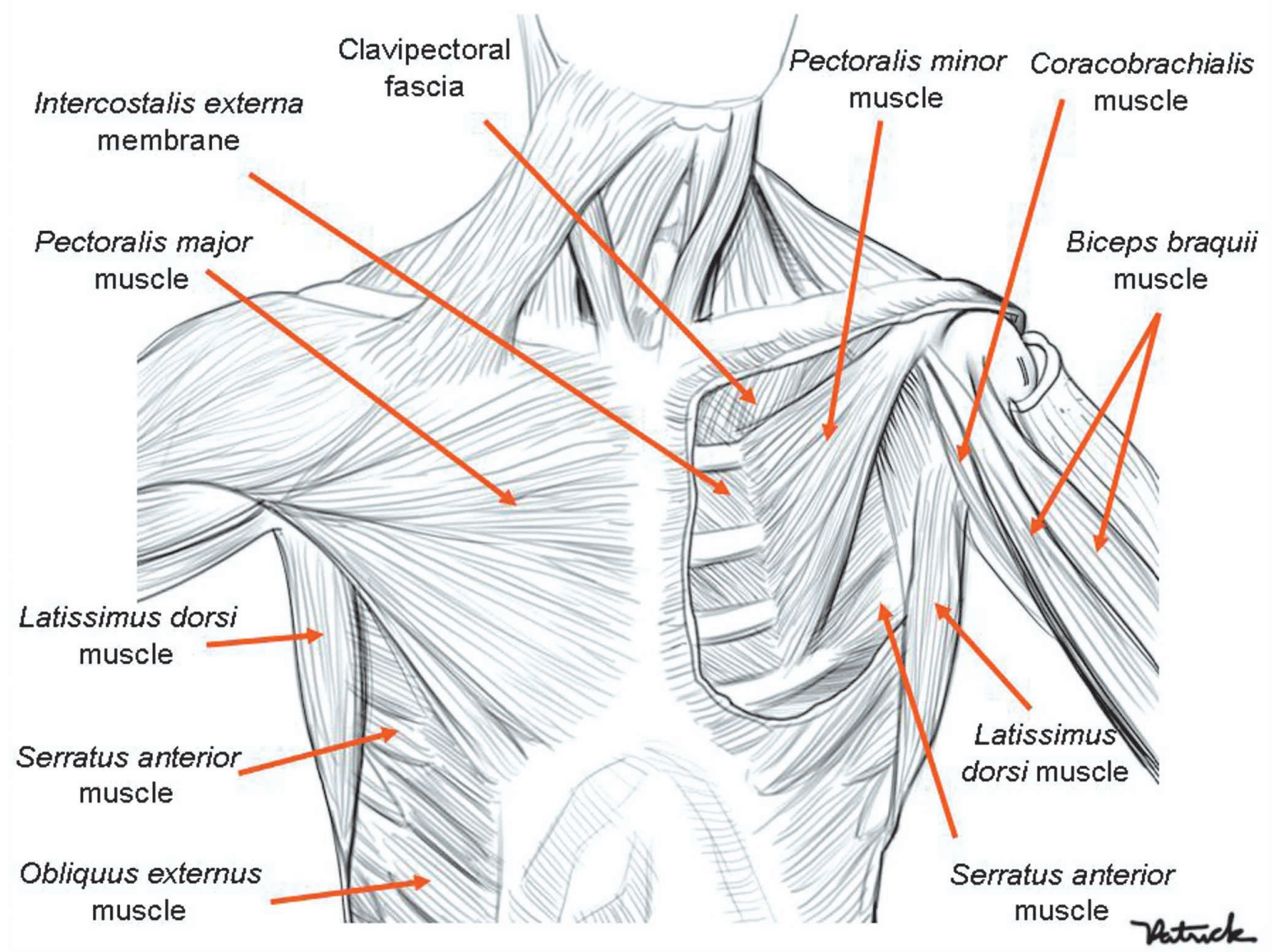

Fig. 1. Muscles of the trunk. On the right side of the figure, the pectoralis major muscle has been extracted in order to view the pectoralis minor muscle (anterior view of the trunk). 


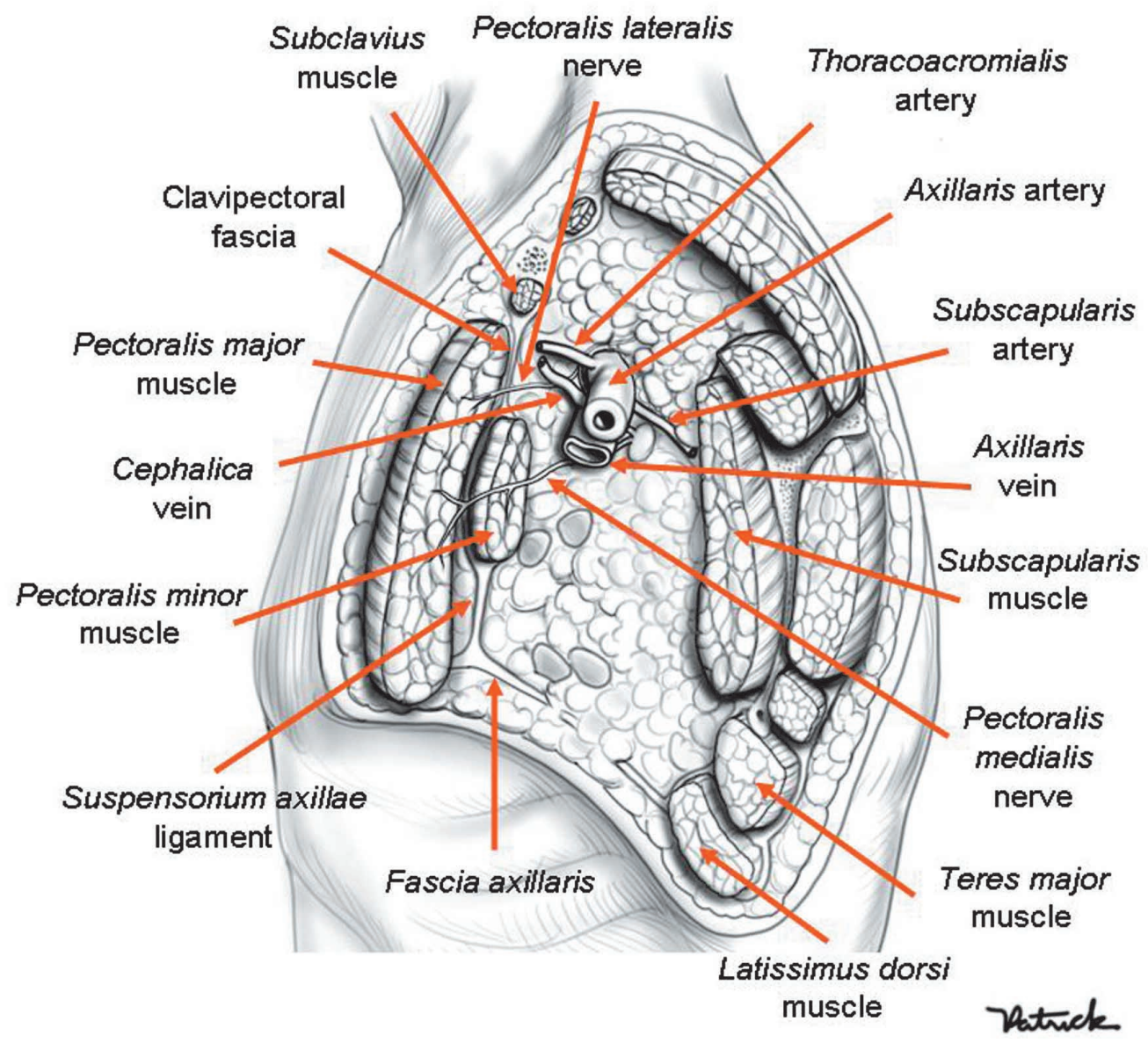

Fig. 2. Sagittal cross-section of the left axillary region, allowing its contents to be seen.

to the chondrocostal junction, and its fibers run superolaterally to be inserted in the inferior face of the middle third of the clavicle. Its function is to stabilize the clavicle in movements of the shoulder. Its innervation is performed by the nerve of the subclavius muscle, a branch of the truncus superior of the plexus brachialis (Williams et al.; Drake et al.).

The latissimus dorsi muscle (Figs. 2 and 3 ) is a wide lamina located on the dorsum of the trunk. It originates from the last six vertebral spinous processes, the iliac crest and the fascia thoracolumbalis. The fibers converge to a single twisted tendon that is inserted in the intertubercular groove of the humerus. Its innervation is performed by the thoracodorsalis nerve, a branch of the fasciculus posterior of the plexus brachialis (Williams et al.; Drake et al.).

The teres major muscle (Fig. 2) originates at the inferior angle of the scapula and rises parallel to the lateral scapular margin towards the medial crest of the intertubercular groove of the humerus, where it is inserted. It receives innervation from the subscapularis inferior nerve, a branch of fasciculus posterior of the plexus brachialis.
Together with the latissimus dorsi muscle, it forms the posterior axillary fold (Williams et al.; Drake et al.).

\section{Anatomy of the axilla.}

1. Limits. The axilla is a pyramidal space located between the upper part of the thoracic wall and the arm. Its shape and size vary according to the position of the arm. Thus, it almost disappears when the arm is completely abducted. The axilla forms a passageway for the vessels and nerves from the neck to reach the upper limb. Anatomically, the axilla is taken to have an apex, a base and four walls, three of which formed by muscles (Snell, 1999; Moore \& Dalley, 2001).

Apex (or cervicoaxillary margin): This corresponds to the threshold zone between the lower part of the neck and the highest part of the axilla. Its components are all bones, namely: limited medially by the first rib, posteriorly by the upper margin of the scapula and medial face of the coracoid process of the scapula, and anteriorly by the clavicle. The arteries and nerves go through the apex from the neck to the upper limb and the veins and lymph vessels go in the opposite direction (Snell; Moore \& Dalley). 


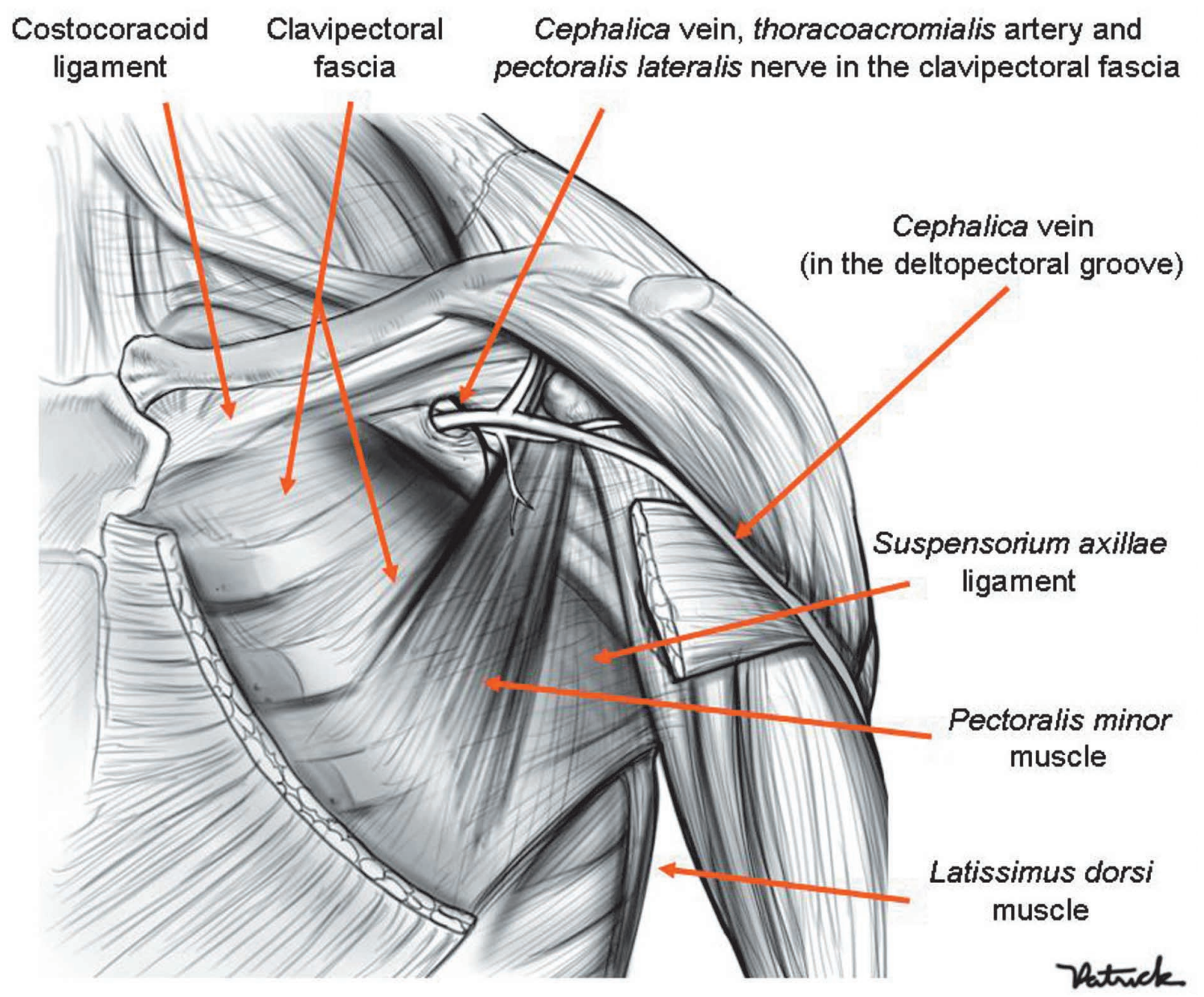

Fig. 3. Pectoralis minor muscle, clavipectoral fascia and suspensorium axillae ligament. The pectoralis major muscle has been extracted for better viewing (anterior view of the thorax).

Base: This is an imaginary downward-turned surface that is wide at the thorax and narrow at the arm and correlates with the skin and thick layer of the fascia axillaris between, anteriorly, the inferior margins of the pectoralis major muscle (anterior axillary fold) and, posteriorly, the latissimus dorsi (posterior axillary fold) (Fig. 2) (Snell; Moore \& Dalley).

Anterior wall: This is formed by the pectoralis major and minor muscles. The whole pectoralis major forms part of the wall, while only the intermediate portion of the pectoralis minor forms part of it. The space between the upper margin of the pectoralis minor and the clavicle is occupied by the clavipectoral fascia, while the space between the lower margin of the pectoralis minor muscle and the dermis at the axillary base is filled by the suspensory ligament of the axilla (suspensorium axillae ligament). In the more cranial portion of the clavipectoral fascia, there is a thickening known as the costocoracoid ligament or Halsted's ligament (terms not recognized by the anatomical terminology), which extends from the first costosternal articulation to the coracoid process of the scapula (Figs. 2 and 3) (Snell; Moore \& Dalley).
Posterior wall: This is formed by the subscapularis muscle in its upper part and the teres major and latissimus dorsi muscles, in its lower part (Fig. 2) (Snell; Moore \& Dalley).

Medial wall: This is formed by the first four ribs with their intercostales muscles, and also the upper part of the serratus anterior muscle (Fig. 1) (Snell; Moore \& Dalley).

Lateral wall: The anterior and posterior walls converge laterally towards the humerus, and the lateral wall is formed by the tendon of the long head (caput longum) of the biceps brachii muscle and, more medially, the coracobrachialis muscle (Fig. 1) (Snell; Moore \& Dalley).

2. Contents of the axilla.The contents of the axilla consist of the axillaris artery and its branches, the axillaris vein and its tributaries, nerves coming mostly from the plexus brachialis, and finally lymph vessels and axillares lymph nodes. In this proximal portion, these elements are surrounded by the axillary sheath, which is a prolongation 
of the pre-vertebral portion of the fascia cervicalis. Between these elements, there is adipose tissue and possibly mammary tissue that is cranially projected from the anterior face of the thorax into the axilla (Williams et al.).

The axillares vessels and the branches of the plexus brachialis cross from the apex of the axilla towards its base, along the lateral wall and closer to the anterior wall, with the axillaris vein anteromedial in relation to the artery. Because of the obliquity of the upper ribs, the axillary neurovascular bundle crosses the first intercostal space when it emerges from behind the clavicle (Williams et al. 1989).

2.1. Axillaris artery. The axillaris artery is a continuation of the subclavia artery. It starts at the lateral margin of the first rib and finishes at the lower margin of the teres major muscle, from which point it starts to be named the brachialis artery (Fig. 4). It is crossed anteriorly by the pectoralis minor muscle, which divides it into three portions: proximal, posterior and distal to the muscle. The first of these is located between the lateral margin of the first rib and the upper margin of the pectoralis minor muscle; the second, posteriorly to the same muscle; and the third, between the lower margin of the pectoralis minor muscle and the lower margin of the teres major muscle (Lockhart et al.; Snell; Moore \& Dalley).

The first portion of the axillaris artery originates the thoracica superior artery; the second portion originates the thoracoacromialis artery and the thoracica lateral artery; and the third portion originates the subscapularis artery and the circunflexae humeri anterior and posterior arteries (Lockhart et al.; Williams et al.; Snell; Moore \& Dalley).

Thoracica superior artery: This artery projects anteromedially above the upper margin of the pectoralis minor muscle, passing between it and the pectoralis major muscle, and reaches as far as the thoracic wall. It irrigates these muscles and the thoracic wall, together with the thoracica interna artery and intercostalis suprema artery. The intercostalis suprema is sometimes absent.

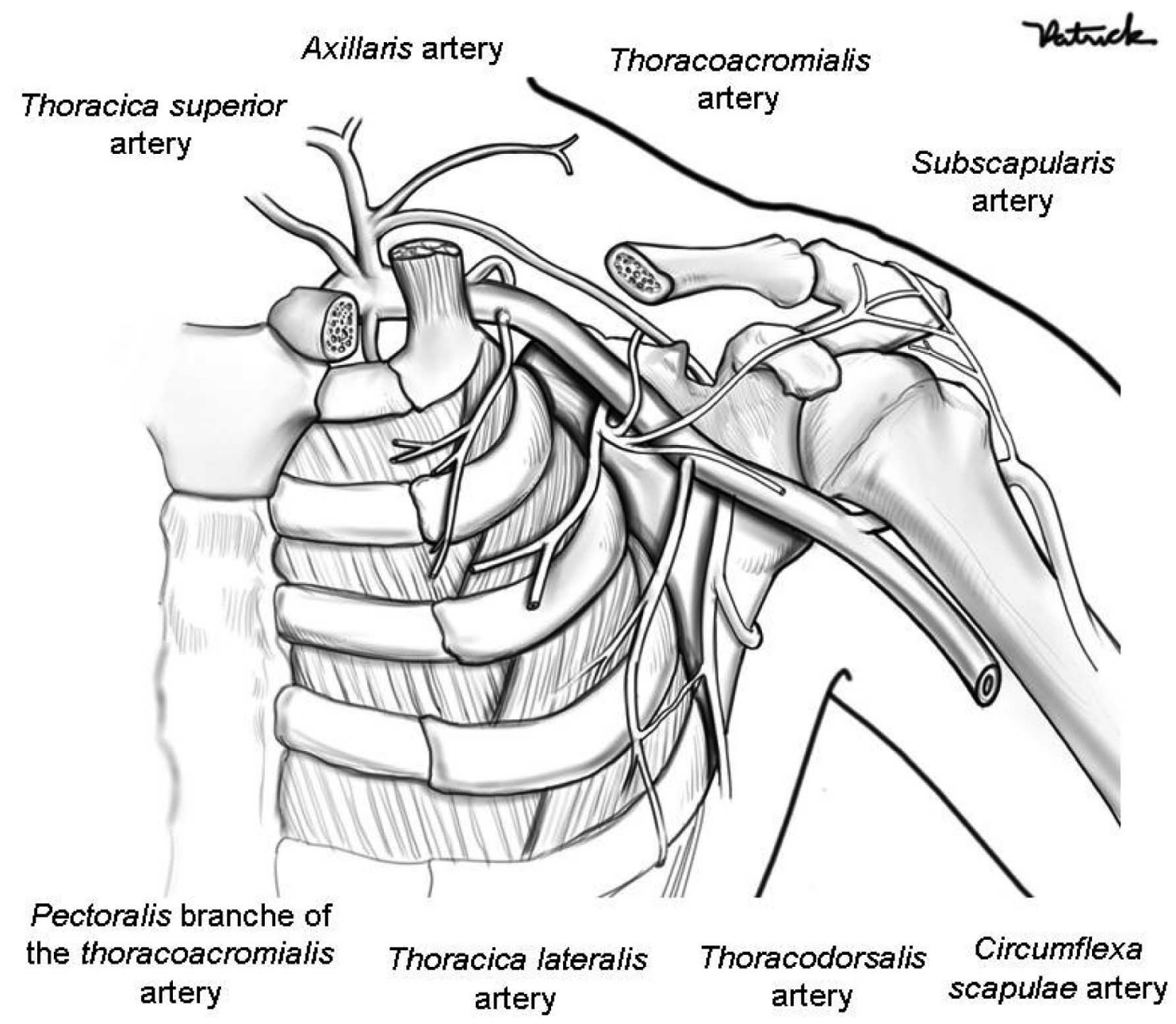

Fig. 4. Axillaris artery and its branches (anterior view of the left axillary region). 
Thoracoacromialis artery: This is a short branch that is initially covered by the pectoralis minor muscle. It runs along the upper margin of this muscle, penetrates the clavipectoral fascia and divides into pectoralis, acromialis, clavicularis and deltoideus branches.

Thoracica lateralis artery: This follows the lower margin of the pectoralis minor muscle as far as the thoracic wall, and irrigates the pectoralis major, serratus anterior and subscapularis muscles and the axillares lymph nodes. In women, this artery is large and it has lateral mammary branches, curving around the lateral margin of the pectoralis major muscle and heading towards the mammary gland.

Subscapularis artery: This is the largest branch of the axillaris artery. It is usually related to the posteroinferior margin of the subscapularis muscle. It irrigates adjacent muscles and the thoracic wall. It is accompanied distally by the thoracodorsalis nerve, which innervates the latissimus dorsi muscle. At around four centimeters from its origin, it originates the circumflexa scapulae artery, which curves around the lateral margin of the scapula and heads towards the infraspinal fossa, crossing the triangular space between the subscapularis muscle (above), the teres major muscle (below) and the long head (caput longus) of the triceps brachii (laterally).

Circunflexa humeri anterior artery: This is a thin artery that arises from the lateral face of the axillaris artery, distally to the lateral margin of the subscapularis muscle. It runs horizontally behind the coracobrachialis muscle and the short head (caput breve) of the biceps brachii muscle, and anteriorly to the surgical neck of the humerus. It reaches the intertubercular groove of the humerus.

Circunflexa humeri posterior artery: This artery is greater in diameter than the previous artery. It arises from the lateral margin of the subscapularis muscle and runs posteriorly with the axillaris nerve through the quadrangular space delimited above by the subscapularis muscle, the capsule of the shoulder joint and the teres minor muscle; below by the teres major, medially by the long head (caput longum) of the triceps brachii muscle and laterally by the surgical neck of the humerus.

2.2. Axillaris vein. The axillaris vein is the most anterior and medial structure in the axillary neurovascular bundle, and is located on the medial side of the axillaris artery (Snell). Between these, there are the pectoralis lateralis nerve, the fasciculus medialis of the plexus brachialis and the ulnaris and cutaneus antebrachii medialis nerves. The cutaneus brachii medialis nerve is medial to the axillaris vein, while the axillares lymph nodes of the lateral group are posteromedial to it. The axillaris vein has a pair of valves close to its distal extremity. It is formed by the union of the brachiales veins (the comitantes veins of the brachialis artery) and the basilica vein, at the lower margin of the teres major muscle. It ends at the lateral margin of the first rib, where it becomes the subclavia vein. Although veins are more abundant in the axilla than arteries, they are anatomically very variable and frequently anastomosed (Williams et al.; Drake et al.). The axillaris vein receives tributaries that generally correspond to branches of the axillaris artery with a few exceptions (Lockhart et al.; Williams et al.).

The veins that correspond to the branches of the thoracoacromialis artery do not fuse to penetrate the axillaris vein via a common tributary. Some enter independently, but other are tributaries of the cephalica vein, which is above the pectoralis major muscle and opens into the axillaris vein close to its transition to the subclavia vein.

The axillaris vein directly or indirectly receives the thoracoepigastricae veins. These are formed by anastomoses of the superficial veins coming from the inguinal region, with tributaries of the axillaris vein (usually the lateral thoracica vein), thus constituting a collateral route that allows venous return when the cava inferior vein is obstructed.

2.3. Axillares lymph nodes. The soft conjunctive tissue of the axillary cavity contains several lymph node groups. Classically, five axillares lymph node groups are described: pectorales, subscapulares, centrales, humerales and apicales (Fig. 5) (Lockhart et al.; Williams et al.; Romrell \& Bland; SBA; Drake et al.).

Pectorales (or anteriores) lymph nodes: This is formed by three to five lymph nodes that are located along the medial wall of the axilla, around the thoracica lateralis vein and the lower margin of the pectoralis minor muscle. This group receives lymph mainly from the anterior thoracic wall, including from the mammary gland. From the pectorales lymph nodes, the lymph passes to the centrales and apicales lymph node groups.

Subscapulares (or posteriores) lymph nodes: This consists of six to seven lymph nodes located along the margin of the posterior axillary wall and the subscapulares vessels. These lymph nodes receive lymph from the posterior face of the thoracic wall and the periscapular region. From this lymph node group, lymphatic efferent fluids go out to the centrales and apicales nodes.

Humerales (or laterales) lymph nodes: This is formed by a group of four to six lymph nodes located 
medially and posteriorly to the axillaris vein, in the proximal segment of the vein, close to the lateral wall of the axilla. This group receives almost all the lymph coming from the upper limb, except the lymph transported by the lymphatic vessels that accompany the cephalica vein, which drains directly to the centrales nodes and, from this, to the apicales lymph nodes.

Centrales lymph nodes: This is formed by three or four large lymph nodes located deeply in relation to the pectoralis minor muscle, close to the base of the axilla, in relation to the second portion of the axillaris artery. Because of its location, this group receives the lymph from the pectorales, subscapulares and humerales nodes. All the lymph from this group drains to the apicales lymph nodes.

Apicales lymph nodes: This group is also known as subclavicular lymph nodes (Romrell \& Bland) (term not officially recognized by the present anatomical terminology [SBA]) and is formed by all the lymph nodes located at the axillary apex, which are located along the medial side of the distal part of the axillaris vein and the first portion of the axillaris artery. The apicales nodes receive lymph coming from all the other axillares lymph node groups, and also the lymph from the lymph nodes that accompany the distal part of the cephalica vein. The efferent lymphatic vessels coming from the apicales nodes join together to form the truncus subclavius, which then joins the truncus jugularis (which drains the lymph from the head and neck) and the truncus bronchomediastinalis (which drains the lymph from the viscera and the thoracic wall), to discharge on the right side into the right lymphatic duct (ductus lymphaticus dexter), and on the left side into the ductus thoracicus. The ductus lymphaticus dexter and the ductus thoracicus discharge into the confluence at the junction of the jugularis interna vein and subclavia vein, on each side.

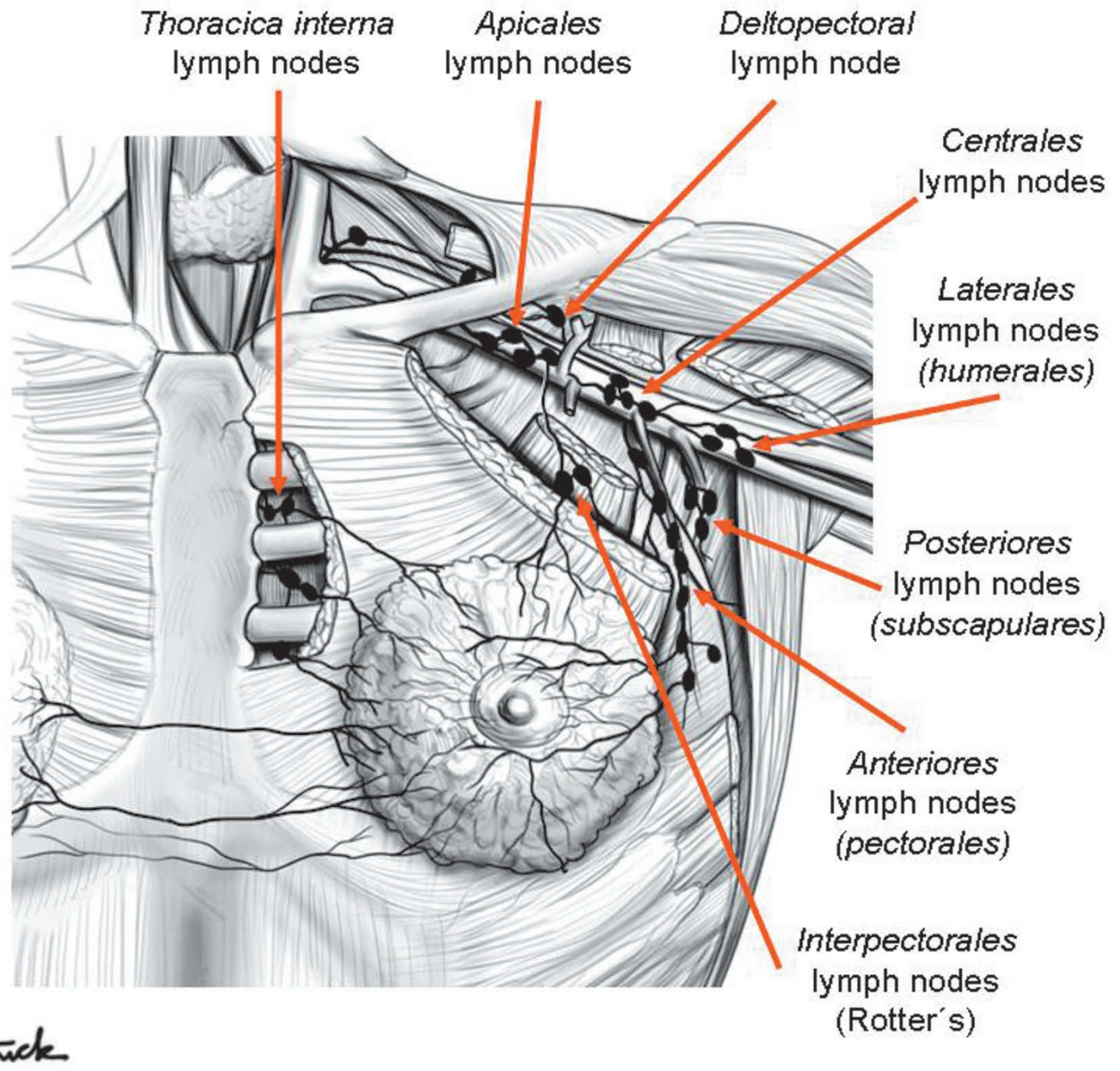

Fig. 5. Axillares, interpectorales and deltopectorales lymph node groups (anterior view of the left axillary region). 
There are two lymph node groups that, although not located within the axilla, deserve special consideration because of their location close to the axilla (Lockhart et al.; Williams et al.; Romrell \& Bland; Drake et al.) (Fig. 5).

Interpectorales lymph nodes or «Rotter's lymph nodes» (SBA): These are difficult to identify during surgery and even in anatomical dissections, and consist of one to four small lymph nodes that are located between the pectoralis major and minor muscles, in association with the pectoral branches of the thoracoacromiales vessels. Their lymph drains directly to centrales lymph nodes, although they may more rarely drain to lymph nodes in the apicales nodes.

Deltopectorales lymph nodes: These nodes are also known as infraclavicular nodes (term not recognized by anatomical terminology [SBA]) and consist of one or two lymph nodes located next to the cephalica vein, in the deltopectoral groove, just below the clavicle. Their efferent fluids penetrate the clavipectoral fascia to drain into the centrales and apicales lymph nodes of the axilla. More rarely, some efferent fluids move anteriorly to the clavicle to end up in the cervicales lymph nodes.

Surgeons usually classify the axillares lymph nodes in levels according to their relationship with the pectoralis minor muscle. Thus, lymph nodes located laterally or below the lower margin of the pectoralis minor muscle are classified as level I lymph nodes. The pectorales (anteriores), subscapulares (posteriores) and humerales (laterales) lymph nodes are included in this level. Lymph nodes located deeply in relation to the pectoralis minor muscle constitute level II lymph nodes and are represented by the centrales lymph nodes and possibly some lymph nodes in the apicales nodes. Finally, lymph nodes located medially or superiorly to the upper margin of the pectoralis minor muscle constitute level III lymph nodes, and these include the apicales lymph nodes (Romrell \& Bland).

2.4. Nerves. Most of the nerves found in the axilla come from the plexus brachialis. Only the intercostobrachialis nerve does not come from this plexus. The plexus brachialis (Fig. 6) is formed anatomically by the primary ventral branches ("roots", radices) of the four inferior cervical nerves and the first thoracic nerve (C5 to T1). There may possibly be contributions from the primary ventral branches of the fourth cervical nerve and the second thoracic nerve (Lockart et al.; Williams et al.). After the components of the plexus emerge from the intervertebral foramens, they are positioned between the scalenus anterior and scalenus medius muscles. In the lower part of the neck, the primary ventral branches of the plexus brachialis joint to form three trunks(trunci): superior (C5 and C6), medius (C7) and inferior (C8 and T1).
Each trunk bifurcates into anterior and posterior divisions (divisiones) as the plexus runs posteriorly to the clavicle via the apex of the axilla. From the mixing of the fibers from the anterior and posterior divisions of the plexus brachialis, the lateralis, medialis and posterior fascicles are formed. The names of the fascicles refer to their relationships with the second portion of the axillaris artery, i.e. they are respectively lateral, medial and posterior in relation to the second portion of the axillaris artery (Snell; Moore \& Dalley).

In accordance with the relationship with the clavicle, the plexus brachialis is, for teaching purposes, divided into the supraclavicular and infraclavicular portions.

In the axilla, the following nerves are found (Lockhart et al.; Williams et al.; Romrell \& Bland; SBA; Drake et al.).

Intercostobrachialis nerve: This corresponds to the lateral cutaneous branch of the second intercostalis nerve. It arises from the second intercostal space and runs obliquely towards the arm, where it anastomoses with the cutaneous brachii medialis nerve, which is a branch of the plexus brachialis. A second intercostobrachialis nerve may also occasionally be observed emerging from the third intercostal space.

Thoracicus longus nerve (Bell's nerve): This originates from the posterior face of the primary ventral branches of C5, C6 and C7. It runs downwards and goes posteriorly to the neurovascular bundle, towards the lateral thoracic wall to innervate the serratus anterior muscle. It is covered by fascia of this muscle.

Subclavius nerve (a branch of the upper trunk of the plexus brachialis): The fibers of this nerve derive mainly from C5 nerve, with contributions from C4 and C6 nerves. It runs downwards to the clavicle and supplies the subclavius muscle.

Pectoralis lateralis nerve (a branch of the fasciculus lateralis of the plexus brachialis): This supplies the pectoralis major muscle, after penetrating the clavipectoral fascia together with the thoracoacromialis artery and cephalica vein (it does not penetrate the pectoralis minor muscle). It sends out a communicating branch to the pectoralis medialis nerve, which innervates the pectoralis minor muscle.

Musculocutaneus nerve (a branch of the fasciculus lateralis of the plexus brachialis): Upon leaving the axilla, this nerve penetrates the coracobrachialis muscle and innervates it. Upon leaving this, it runs between the biceps brachii and brachialis muscles and supplies them. It continues superficially and laterally as a cutaneus antebrachii lateralis nerve in the forearm. 
Medianus nerve: This is formed by the lateral and medial roots coming from the fasciculus lateralis and fasciculus medialis, respectively. It innervates most of the flexors and pronators muscles of the forearm and five intrinsic muscles of the hand, and it picks up the sensitivity of the skin of part of the hand and fingers.

Pectoralis medialis nerve (a branch of the fasciculus medialis of the plexus brachialis): This nerve penetrates the pectoralis minor muscle to supply it, and continues to also innervate the pectoralis major muscle.

Cutaneus brachii medialis nerve (a branch of the fasciculus medialis of the plexus brachialis): This is a thin nerve that picks up the sensitivity of the medial face of the arm and the superior medial face of the forearm.

Cutaneus antebrachii medialis nerve (a branch of the fasciculus medialis of the plexus brachialis): This nerve is bigger than the preceding one and is located between the axillaris artery and vein, supplying the skin of the medial face of the forearm.

Ulnaris nerve (a branch of the fasciculus medialis of the plexus brachialis): This runs the whole length of the arm without innervating anything. In the forearm it innervates two flexors muscles and in the hand it is the principal nerve, since it innervates the majority of its intrinsic muscles.

Thoracodorsalis nerve (a branch of the fasciculus posterior of the plexus brachialis): This innervates the latissimus dorsi muscle. It accompanies the subscapularis and thoracodorsalis arteries anteriorly to the subscapularis muscle.

Subscapularis superioris nerve (a branch of the fasciculus posterior of the plexus brachialis): This is located medially to the thoracodorsalis neurovascular bundle and innervates the subscapularis muscle.

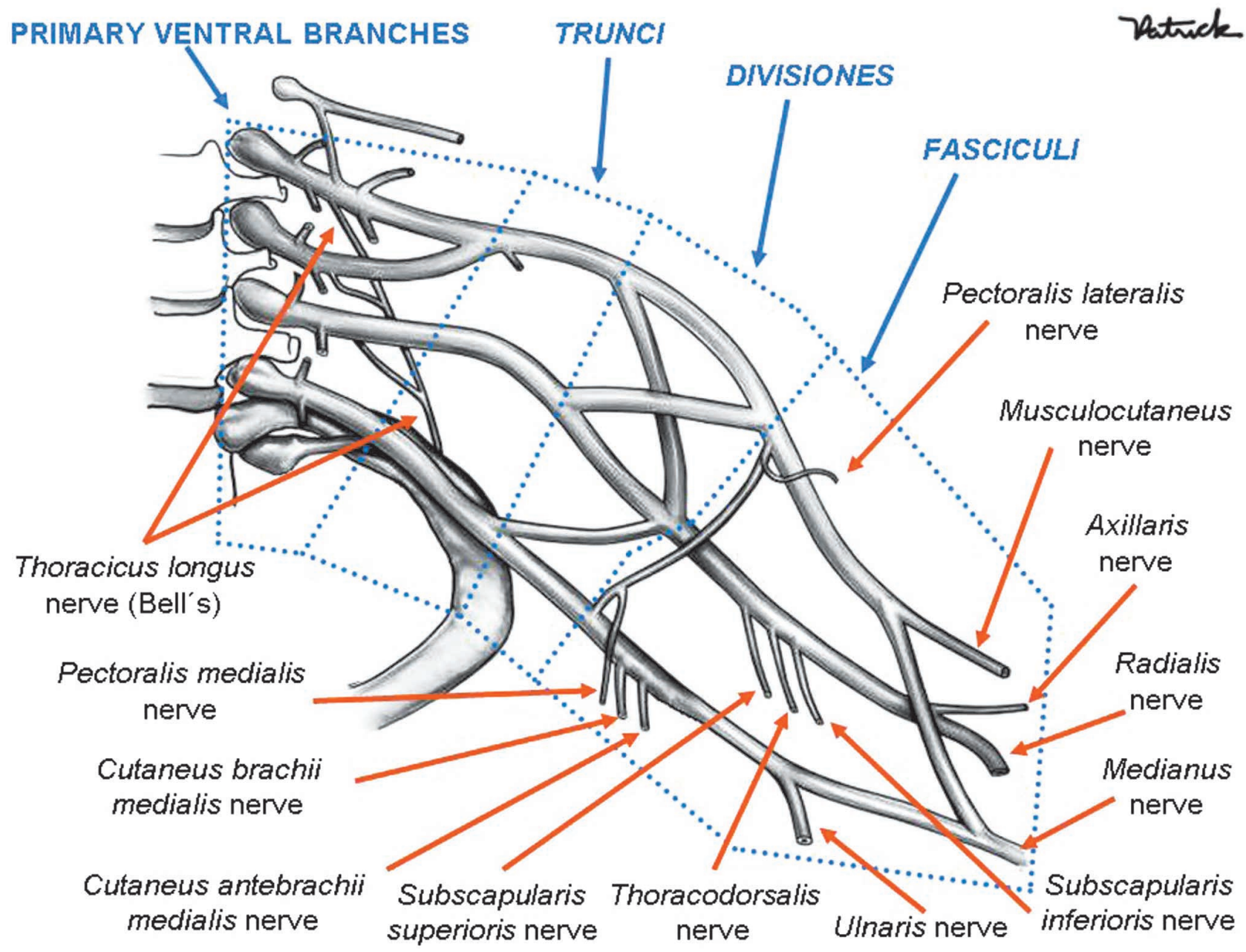

Fig. 6. Schematic representation of the left plexus brachialis. 
Subscapularis inferioris nerve (a branch of the fasciculus posterior of the plexus brachialis): This innervates the teres major muscle and the lower part of the subscapularis muscle. It is located laterally to the thoracodorsalis neurovascular bundle.

Axillaris nerve (a branch of the fasciculus posterior of the plexus brachialis): This supplies the teres minor muscle as it leaves the axillary space through the quadrangular space. It innervates the deltoideus muscle from its deep posterior part and continues as a cutaneus brachii lateralis superioris nerve, innervating the skin on the lower half of the deltoideus muscle.

Radialis nerve (a branch of the fasciculus posterior of the plexus brachialis): This is the biggest nerve in the plexus brachialis. After leaving the axilla, it penetrates the groove of the radialis nerve of the humerus, where it may be damaged in the event of humeral fractures. It innervates all the extensors muscles of the posterior compartments of the arm and forearm, and also the supinator and brachioradialis muscles. It originates the cutaneus brachii and antebrachii posteriores nerves, and also the cutaneous brachii lateralis inferior nerve.

Injuries to nerves may occur during axillary lymphonodectomy. By respecting the axillaris vein as the most cranial limit of the field of lymph node dissection, the fascicles and different branches of the plexus brachialis will be protected from inadvertent lesion. Nonetheless, some nerves may suffer injury during lymphonodectomy. The intercostobrachialis nerve is frequently sectioned because it crosses the axilla obliquely towards the arm and is located within the product from the lymph node dissection. Because this is a sensitive nerve, the impairment caused will consist of hyposthesia of the skin that covers the axilla and medial face of the arm. The thoracicus longus nerve runs laterally along the thoracic wall and is usually detached from its bed when the fascia of the serratus anterior muscle is removed, such that the nerve adheres to the dissection product. If this situation is not noticed, it may result in sectioning of the nerve and consequent denervation of the serratus anterior muscle, which causes posterior displacement of the scapula ("winged scapula") (Romrell $\&$ Bland). The thoracodorsalis nerve may suffer injury if the subscapulares vessels are damaged or ligated. The subscapulares superior and inferior nerves become damaged when the fascia of the subscapularis muscle is extracted and the field of dissection extends posteriorly to the axillaris vein, or over the latissimus dorsi muscle superolaterally (subscapularis inferior nerve). Ligation of the thoracoacromialis artery beyond its emergence from the clavipectoral fascia will cause sectioning of the pectoralis lateralis nerve. Injury to the pectoralis medialis nerve occurs when the pectoralis minor muscle is extracted, or when the space between the pectoral muscles is extensively dissected.

\section{Anatomy of the breasts.}

1. Anatomical description. The breasts have a conical shape and are located, one on each side, within the subcutaneous layer of the thoracic wall, anteriorly to the pectoralis major muscle. They extend superiorly as far as the level of the second rib, inferiorly as far as the level of the sixth or seventh ribs, laterally as far as the anterior axillary line (sometimes as far as the middle axillary line) and medially they reach the lateral margin of the sternum. Posteriorly, they make contact with the fascia of the pectoralis major, serratus anterior and obliquus externus muscles and the most cranial portion of the rectus abdominis muscle (Netter, 1996; Romrell \& Bland).

Its base is circular and measures around 10 to $12 \mathrm{~cm}$, but its volume is very variable. The weight of a non-lactating breast ranges from 150 to $225 \mathrm{~g}$, while a lactating breast may exceed 500g in weight. The breasts of nulliparous women have a hemispherical shape, while those of multiparous women are broader and pendulant. With aging, the breast volume decreases and the breast becomes less firm, flatter and pendulant (Romrell \& Bland).

Three portions are distinguished anatomically: the gland itself (glandula mammaria), the mammary papilla ( $p a-$ pilla mammariae) and the areola (areola mammae). The mammary gland is formed by fifteen to twenty lobes (lobi glandulae mammariae) that are arranged radially and delimited by septa of conjunctive tissue and adipose tissue in the subcutaneous layer (Fig. 7). The mammary parenchyma is more abundant in the upper half of the gland, especially in the superolateral quadrant. The mammary tissue frequently extends beyond the apparent outline of the breast, projecting towards the axilla as an axillary process (sometimes called tail of Spence [SBA]). The principal duct of each lobe, the lactiferous duct (ductus lactiferi), opens separately into the mammary papilla. In turn, the lobe is formed by smaller functional units, the lobules (lobuli), from which ducts converge towards the main duct of the lobe (Lockhart et al.; Williams et al.).

The subcutaneous layer (tela subcutanea) completely surrounds the gland, except in the region of the papilla (Williams et al.; Netter). It needs to be clarified that the subcutaneous layer was in the past named the superficial fascia (Hollinshead \& Rosse, 1991). The part of this layer located immediately in front of the fascia of the pectoralis 
major muscle was erroneously called the deep layer of the superficial fascia (Romrell \& Bland). In the subcutaneous layer, fascicles of conjunctive tissue are observed to permeate the lobes and lobules, particularly in the upper part of the gland, which cross the breast anteroposteriorly, extending from the dermis to the part of the subcutaneous layer next to the fascia of the pectoralis major muscle. These fascicles are known as the suspensory (or Cooper's [SBA]) ligaments of the breast (suspensoria mammaria ligament). Neoplasms of the breast may affect them and cause localized retraction of the overlying skin (Netter; Romrell \& Bland).

Although not officially recognized by the present anatomical terminology (SBA), the space located between the deep part of the subcutaneous layer and the muscular fascia of the pectoralis major muscle is known as the retromammary bursa, submammary serous bursa or also Chassaignac's bursa (Netter; Romrell \& Bland). It is easily identified during mastectomy. This space contributes towards the mobility of the breast on the thoracic wall.
The mammary papilla represents the apex of the cone and contains the opening for all the lactiferous ducts from the lobes. Close to the apex of the papilla, each duct presents a distal saclike dilatation known as the lactiferous sinus (sinus lactiferi) (Williams et al.; Netter; Romrell \& Bland) (Fig. 7). It is worth emphasizing that, although the term nipple is habitually utilized in clinical practice (Netter), it is recommended that the expression mammary papilla should be utilized in the anatomical terminology (SBA).

The areola is a slightly raised disc-shaped area of variable size surrounding the papilla. Initially, it has a rosy hue, but becomes irreversibly pigmented (chestnut brown) from the second month of gestation. On its surface, it presents granular and pointlike elevations known as areolar tubercles (tubercula areolares) or Montgomery's tubercles (Netter; Romrell \& Bland). These correspond to the anatomical representation of glands with intermediate histological structure between sudoriparous and mammary glands, the areolar glands (glandulae areolares) (Fawcett, 1994).

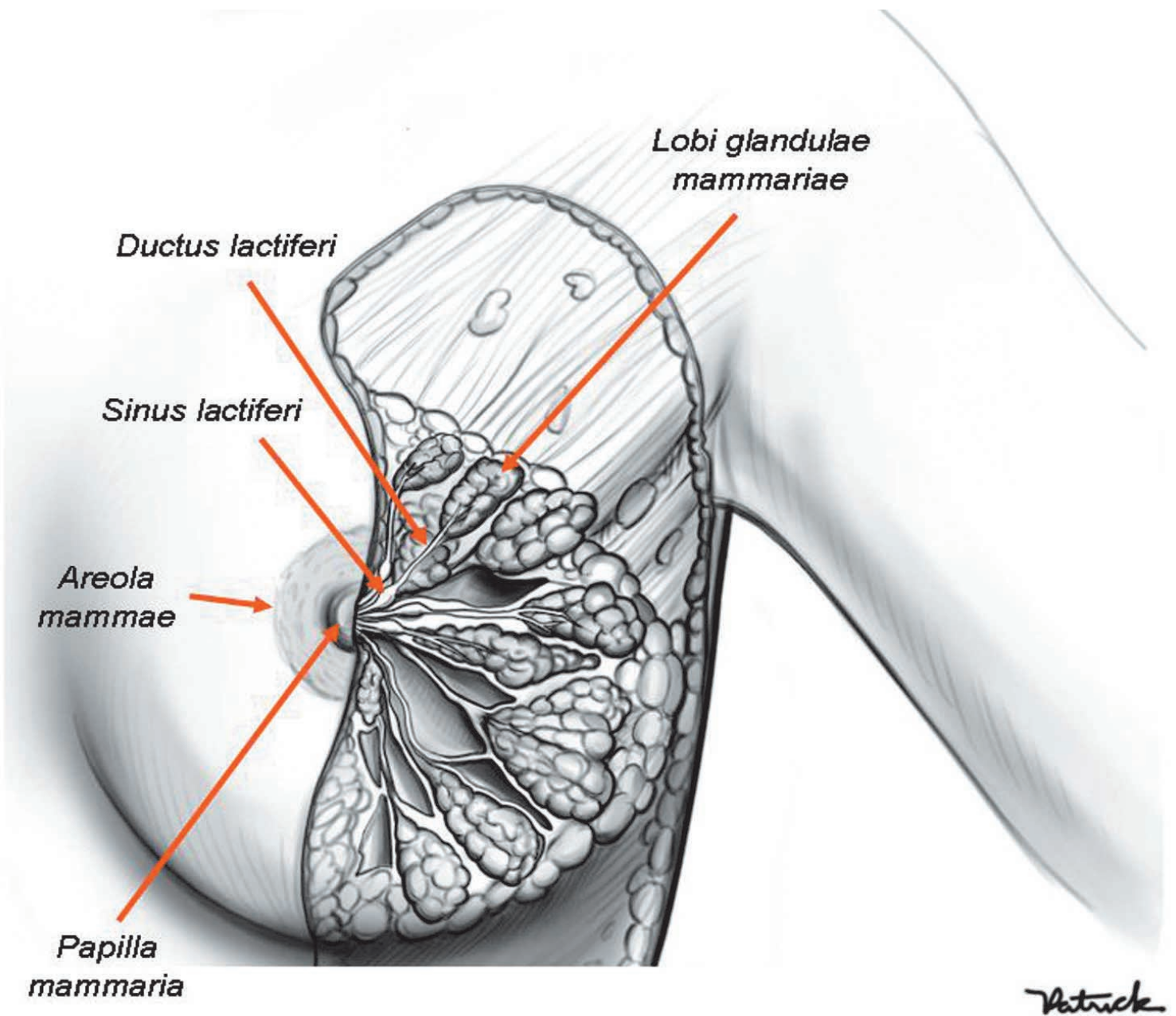

Fig. 7. Right breast. The skin and subcutaneous layer have been extracted in order to view the lobi glandulae mammariae, ductus lactiferi and sinus lactiferi (anterior view). 
2. Vascularization. The mammary irrigation is done by means of medial and lateral mammary branches of vessels (rami mammarii mediales and laterales) (Romrell \& Bland) (Fig. 8). The mammarii mediales branches originate from penetrating branches of the thoracica interna artery (a branch of the subclavia artery), which emerges from the second, third and fourth intercostal spaces (Williams et al.). In the past, this artery was named the internal mammary artery (Lockhart et al.; Hollinshead \& Rosse), but this name should no longer be used. The mammarii laterales branches have multiple origins, namely: 1) thoracica superior artery (a branch of the first portion of the axillaris artery); 2) thoracica lateral artery (a branch of the second portion of the axillaris artery); 3) pectorales branches of the thoracoacromialis artery (a branch of the second portion of the axillaris artery); 4) penetrating branches of the intercostales posteriores arteries of the second, third and fourth spaces. The mammarii laterales branches predominantly originate from the thoracica lateral artery (formerly called the external mammary artery) (Williams et al.; Hollinshead \& Rosse).

The venous drainage from the mammary gland is done by veins that generally accompany the arteries. Medially, the veins drain to the thoracica interna vein (a tributary of the brachiocephalica vein), and laterally to the axillaris vein. Drainage is also done by the intercostales posteriores veins. Those of the second and third intercostal spaces drain to the intercostalis suprema vein, which in the right side is a tributary of the arch of the azygos vein and on the left side, of the left brachiocephalica vein. Those of the fourth space drain to the azygos vein (on the right side) and hemiazygos vein (on the left side) (Lockhart et al.; Williams et al.; Romrell \& Bland; Drake et al.). The superficial (cutaneous) mammary veins are presented profusely anastomosed and easily visible during gestation, the Haller's vascular network (Netter). Around the mammary papilla, the veins form an anastomotic venous plexus of circular shape, known as the venous circle (Netter), a term that is not applied in the anatomical terminology (SBA).

3. Lymphatic drainage. Four intercommunicating lymphatic plexuses in the breast are described: one located in the dermis (cutaneous plexus), one in the superficial subcutaneous region (subcutaneous plexus), one in the fascia of the pectoralis major muscle (fascial plexus) and the last in the mammary gland, involving the lobes and ducts (glandular plexus). This last one communicates by means of lymphatic vessels that accompany the lactiferous ducts with a region of the subcutaneous plexus located immediately below the areola that is known as the subareolar plexus (or Sappey's plexus). The fascial plexus establishes communication with the subcutaneous plexus by means of the lymphatic vessels along the fibrous fascicles of the stroma (Williams et al.; Romrell \& Bland).
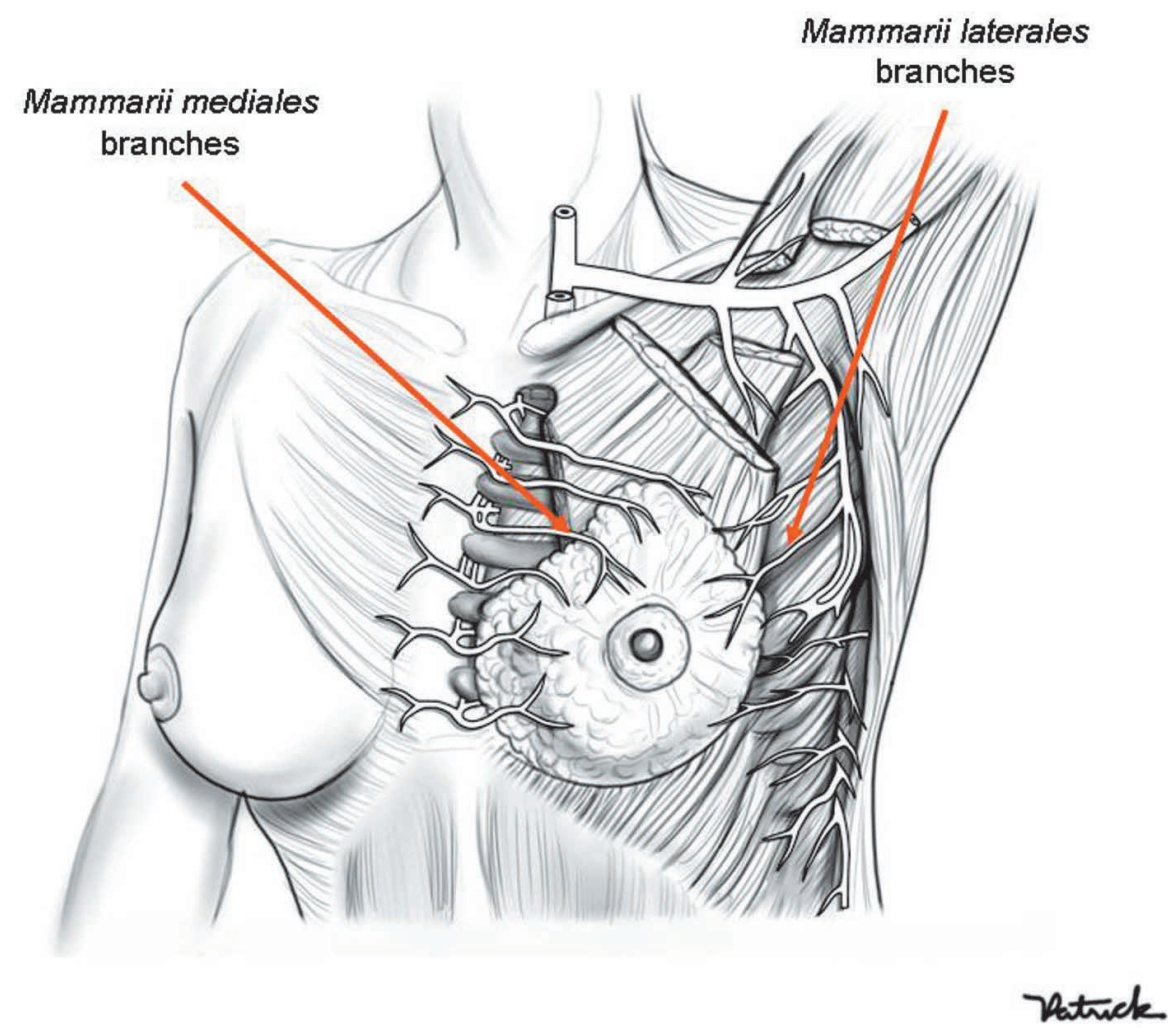

Fig. 8. Arterial branches to the breast (anterior view of the trunk). 
The deep and superficial (cutaneous) lymphatic drainage is performed by the lateral and medial efferent lymphatic vessels, to lymph nodes respectively in the axilla and along the thoracicae internae vessels (Fig. 5). The medial efferent vessels of one breast may anastomose with those of the contralateral breast, thus establishing intermammary lymphatic anastomoses (intermammary communication). This explains the occasional metastatic involvement of contralateral axillares lymph nodes in relation to neoplasm in the other breast (Romrell \& Bland; Netter). The lateral efferent lymphatic vessels initially lead to the pectorales lymph nodes that are located along the thoracicae internae vessels, close to the lower margin of the pectoralis major and minor muscles, and sometimes directly to the lymph nodes along the subscapulares vessels (subscapulares lymph nodes). The lymph vessels may occasionally accompany the intercostales posteriores vessels and lead to the intercostales lymph nodes, which are located close to the heads of the ribs, from where the drainage is to the ductus thoracicus (Lockhart et al.; Williams et al.; Romrell \& Bland).

The fascial lymphatic plexus does not have significant participation in the drainage of the breast, but serves as an alternative route in the event of obstruction of the principal route. The lymph of the fascial plexus drains to efferent vessels that penetrate the pectoralis major and minor muscles and, from there, drain to the apicales nodes of the axilla (Romrell \& Bland). On this transpectoral drainage route, also known as Groszman's route (Netter), an intermediate group of lymph nodes is described (between one and four in total), arranged along the thoracoacromiales vessels and situated between the pectoralis major and minor muscles. These lymph nodes are known as interpectorales lymph nodes «or Rotter's lymph nodes (SBA)» and are rarely brought into view during surgery or in anatomical specimens (Fig. 5).

Although there is a belief that the lymph nodes along the thoracicae internae vessels receive the lymph from the medial quadrants, studies have shown that both the axillares lymph nodes and the thoracicae internae lymph nodes receive lymph from all the mammary quadrants, thanks to the widespread lymphatic network. There is, however, clear predominance of drainage to the axilla, and this route corresponds to more than three quarters of the mammary lymphatic drainage. The most cranial part of the breast may have lymphatic drainage directly towards the apicales lymph nodes of the axilla (Romrell \& Bland).

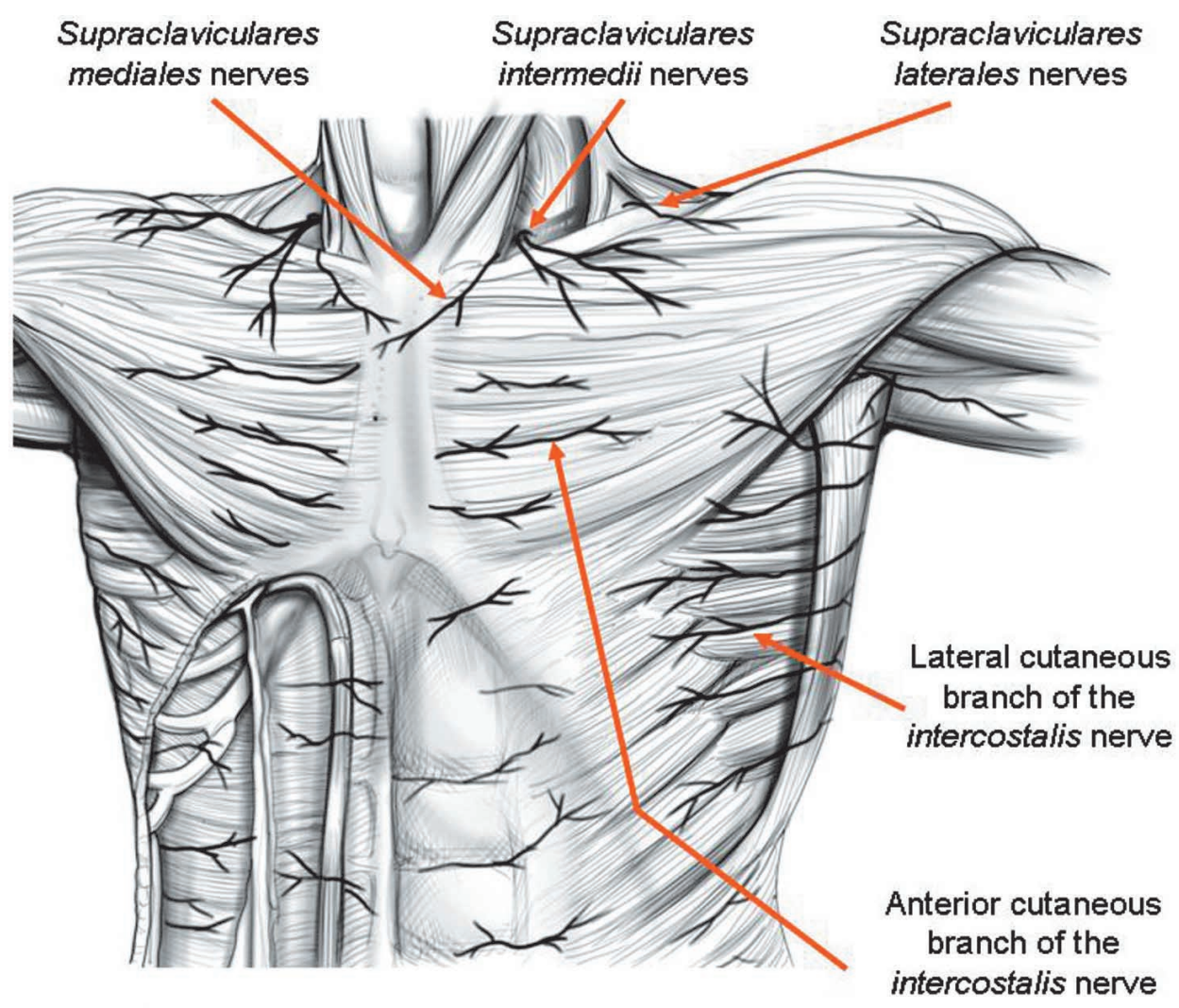

Datuck

Fig. 9. Innervation of the breast (anterior view of the trunk). 
The lymph from the breasts may occasionally drain via lymphatic vessels that accompany the lateral cutaneous branches of the intercostales vessels and drain to the intercostales posteriores lymph nodes, which are located close to the heads of the ribs. From there, the lymph continues to the ductus thoracicus. The lymphatic vessels from the breasts may also occasionally drain to the liver and subdiaphragmatic plexus, by means of the abdominal lymphatic vessels (Gerota's paramammary route) (Netter; Romrell \& Bland).

4. Innervation. The sensitivity of the breast is picked up by means of medial, lateral and superior mammarii branches of nerves (Fig. 9). The medial branches correspond to the anterior cutaneous branch of the intercostales nerves of the second to sixth spaces. The lateral branches correspond to the communicating branch and the anterior division of the lateral cutaneous branch of the same nerves. The only exception is the lateral cutaneous branch of the second intercostalis nerve, named the intercostobrachialis nerve, which runs to the base of the axilla and the superior medial face of the arm. The superior branches run to the most cranial region of the breasts and correspond to the supraclaviculares mediales, intermedii and laterales nerves (branches of the plexus cervicalis). The mammary papilla is plentifully supplied by free and branched nerve ends (Lockhart et al.; Williams et al.; Romrell \& Bland; Drake et al.).

Sympathetic fibers reach the breast by means of the abovementioned nerves for vasomotor control, but not for secretion activities, which are controlled by hormonal mechanisms. There are no fibers of parasympathetic nature in the breasts (Fawcett).

MACÉA, J. R. \& FREGNANI, J. H. T. G. Anatomía de la pared torácica, axila y mama. Int. J. Morphol., 24(4):691-704, 2006.

RESUMEN: Para un adecuado tratamiento de pacientes con cáncer de mama, los mastologistas deben tener un completo conocimiento de la anatomía de la pared torácica, axila y mama. Sin embargo, la descripción de la anatomía clásica se hace dificultosa en los libros para obtener una óptica visión sobre esta materia, debido a que los textos tratan estos elementos separadamente. Con el objetivo de resolver esta dificultad, los autores hacen una extensa revisión, describen los músculos, vasos sanguíneos y nervios de la pared torácica y de la axila, que son de interés para los mastologistas. Fue descrita la axila, dando énfasis a sus límites, pared y contenidos, y especialmente, a los linfonodos de la región. Finalmente, se describió la anatomía de la mama, su topografía, inervación, vascularización, y drenaje linfático haciendo una relación entre la anatomía y la clasificación rutinaria del grupo de linfonodos utilizada por los mastologistas.

PALABRAS CLAVE: pared torácica; Axila; mama; Anatomía.

\section{REFERENCES}

Drake, R. L.; Vogl, W. \& Mitchell, A. W. Gray's Anatomia clínica para estudantes. Rio de Janeiro, Elsevier, 2005.

Fawcett, D. W. A textbook of Histology. New York, Chapman \& Hall, 1994.

Hollinshead, W. H. \& Rosse, C. Anatomia. 4a ed. Rio de Janeiro, Interlivros, 1991.

Lockhart, R. D.; Hamilton, G. F. \& Fyfe, F. W. Anatomy of the human body. London, Faber and Faber Limited, 1959.

Moore, K. L. \& Dalley, A. F. Anatomia orientada para a clínica. $4^{\mathrm{a}}$ ed. Rio de Janeiro, Guanabara-Koogan, 2001.

Netter, F. H. The Ciba collection of medical illustrations. A compilation of painting $s$ on the normal and pathologic anatomy of the reproductive system. $10^{\text {th }} \mathrm{ed}$. New Jersey: Ciba-Geigy Corporation; 1996.

Romrell, L. J. \& Bland, K. I. Anatomy of the breast, axilla, chest wall, and related metastatic sites. In: Bland KI,

Copeland EM, editors. The breast comprehensive management of benign and malignant disease. 2nd ed. Philadelphia, WB Saunders Company, 1998.

SBA (Sociedade Brasileira de Anatomia). Terminologia Anatômica. Terminologia Anatômica Internacional. $1^{\mathrm{a}}$ edição. São Paulo, Manole, 2001.

Snell, R. S. Anatomia clínica para estudantes de Medicina. $5^{\text {a }}$ ed. Rio de Janeiro, Guanabara-Koogan, 1999.

Williams, P. L.; Warwick, R.; Dyson, M. \& Bannister, L. H. Gray's anatomy. $37^{\text {th }}$ ed. London, Churchill Livingstone, 1989.

Correspondence to: Dr. José Rafael Macéa Departamento de Morfologia

Faculdade de Ciencias Médicas da Santa Casa de São Paulo

Rua Cesario Mota Júnior, 61, Vila Buarque, CEP 01221-020

São Paulo-SP, BRASIL

E-mail:jrmacea@hotmail.com / mdfregnani@terra.com.br
Received: 16-08-2006

Accepted: 11-10-2006 